\title{
Minimally invasive removal of lumbar intradural extramedullary lesions using the interlaminar approach
}

\author{
*Yong-Jian Zhu, MD, PhD, ${ }^{1}$ Guang-Yu Ying, MD, ${ }^{1}$ Ai-Qin Chen, MN, ${ }^{1}$ Lin-Lin Wang, PhD, ${ }^{2}$ \\ Dan-Feng Yu, MD, ${ }^{1}$ Liang-Liang Zhu, MD, ${ }^{1}$ Yu-Cheng Ren, MD, ${ }^{1}$ Chen Wang, MD, ${ }^{1}$ \\ Peng-Cheng Wu, MD, ${ }^{1}$ Ying Yao, MD, ${ }^{1}$ Fang Shen, MD, PhD, ${ }^{3}$ and Jian-Min Zhang, MD, PhD'
}

1Department of Neurosurgery, Second Affiliated Hospital of Zhejiang University School of Medicine, Hangzhou; ${ }^{2}$ Department of Physiology, Zhejiang University School of Medicine, Hangzhou; and ${ }^{3}$ Department of Neurosurgery, Ningbo No. 2 Hospital, Ningbo, China

OBJECT Posterior midline laminectomy or hemilaminectomy has been successfully applied as the standard microsurgical technique for the treatment of spinal intradural pathologies. However, the associated risks of postoperative spinal instability increase the need for subsequent fusion surgery to prevent potential long-term spinal deformity. Continuous efforts have been made to minimize injuries to the surrounding tissue resulting from surgical manipulations. The authors report here their experiences with a novel minimally invasive surgical approach, namely the interlaminar approach, for the treatment of lumbar intraspinal tumors.

METHODS A retrospective review was conducted of patients at the Second Affiliated Hospital of Zhejiang University School of Medicine who underwent minimally invasive resection of lumbar intradural-extramedullary tumors. By using an operative microscope, in addition to an endoscope when necessary, the authors were able to treat all patients with a unilateral, paramedian, bone-sparing interlaminar technique. Data including preoperative neurological status, tumor location, size, pathological diagnosis, extension of resections, intraoperative blood loss, length of hospital stay, and clinical outcomes were obtained through clinical and radiological examinations.

RESULTS Eighteen patients diagnosed with lumbar intradural-extramedullary tumors were treated from October 2013 to March 2015 by this interlaminar technique. A microscope was used in 15 cases, and the remaining 3 cases were treated using a microscope as well as an endoscope. There were 14 schwannomas, 2 ependymomas, 1 epidermoid cyst, and 1 enterogenous cyst. Postoperative radiological follow-up revealed complete removal of all the lesions and no signs of bone defects in the lamina. At clinical follow-up, 14 of the 18 patients had less pain, and patients' motor/sensory functions improved or remained normal in all cases except 1.

CONCLUSIONS When meeting certain selection criteria, intradural-extramedullary lumbar tumors, especially schwannomas, can be completely and safely resected through a less-invasive interlaminar approach using a microscope, or a microscope in addition to an endoscope when necessary. This approach was advantageous because it caused even less bone destruction, resulting in better postoperative spinal stability, no need for facetectomy and fusion, and quicker functional recovery for the patients. Individualized surgical planning according to preoperative radiological findings is key to a successful microsurgical resection of these lesions through the interlaminar space.

http://thejns.org/doi/abs/10.3171/2015.5.FOCUS15182

KEY WORDS lumbar schwannomas; minimally invasive; interlaminar approach; microscope; endoscope

ABBREVIATIONS ASIA = American Spinal Injury Association; CISS = constructive interference in steady state; GTR = gross-total resection; VAS = visual analog scale; VRT = volume-rendering technique.

SUBMITTED April 1,2015. ACCEPTED May 20, 2015

INCLUDE WHEN CITING DOI: 10.3171/2015.5.FOCUS15182.

DISCLOSURE This study was supported by the Science and Technology Department of Zhejiang Province (grant no. 2007C33042) and Ningbo Key Clinical Specialty

(Orthopedics; grant no. 2013-88).

* Drs. G. Y. Ying and F. Shen contributed equally to this work. 
I NTRASPINAL tumors are lesions located either outside the spinal cord (intradural-extramedullary or extradural) or inside the spinal cord (intramedullary). ${ }^{43}$ The traditional surgical procedures for resection of these pathologies involve subperiosteal muscle stripping, hemilaminectomy, or even extensive laminectomy. ${ }^{46}$ For those lesions affecting the foraminal regions, an additional ipsilateral facetectomy might be required. ${ }^{13,24}$ Therefore, in view of the increased risks of spinal instability and deformities associated with these radical operations, especially when the cervical or lumbar spine is operated on, reconstructive fusion procedures are usually required..$^{15,19,38,39,48}$ One unique anatomical feature of the lamina of the lumbar spine is its relatively wide wedge-shaped interlaminar space, widest at the center while narrowed at either end. To prevent the aforementioned complications, alternative, less-invasive surgical techniques are being developed by taking advantage of both the natural opening or passage in the bones of the spine and innovations in surgical instruments. ${ }^{37,49}$ The purpose of this present study was to report experiences with a novel minimally invasive technique, namely microsurgical resection of lumbar lesions via a "lossless" interlaminar approach. The authors use the word "lossless" to convey the concept of the most minimal injury ever possible to surrounding bony tissues while successfully removing the lesions in the spinal canal. This method is technically feasible for the following reasons: first, patients with intradural tumors at the lumbar spine usually manifest signs and symptoms in the early stages. ${ }^{32}$ And the availability of MR images also contribute to early detection of tumors, e.g., when the diameter is $2 \mathrm{~cm}$ or smaller. Second, schwannomas are the most common intradural-extramedullary spinal tumors that are found in the lumbar spine, and they typically do not adhere to surrounding spinal cord, nerves, or vessels, and are relatively easy to remove via microsurgical manipulation. ${ }^{27,30}$ Third, because of the absence of the spinal cord, the lumbar cistern is quite spacious. In addition, schwannomas usually have a downward blood supply that originates from the same artery feeding the affected spinal nerve root above. ${ }^{23}$ Therefore, exposure and coagulation of the feeding artery at the upper (proximal) edge of the tumor could effectively control tumor bleeding during the operation and thus may help to ensure a clear visual field under the microscope and reduce the risks of nerve injury as well. ${ }^{26}$ Lastly, both preoperative gradientecho constructive interference in steady state (CISS) MRI sequencing and 3D CT reconstruction of the spinal canal with the volume-rendering technique (VRT) are helpful in terms of investigating the spatial relationship between the tumor and the affected spinal nerve root; therefore, precise surgical planning can be customized for each patient. ${ }^{9,16,25}$ By sparing the need for complete or even partial laminectomy and/or facetectomy and subsequent spinal fusion, the authors suggest that this novel, minimally invasive interlaminar treatment of intradural-extramedullary lumbar tumors could become increasingly popular in spinal surgery.

\section{Methods}

\section{Study Population}

A retrospective review was conducted of patients who underwent minimally invasive resection of lumbar intraspinal tumors between October 2013 and March 2015 in the Department of Neurosurgery, Second Affiliated Hospital of Zhejiang University School of Medicine. Approval for the study was obtained from the Medical Ethics Committee of the Second Affiliated Hospital of Zhejiang University School of Medicine. Preoperative evaluation consisted of clinical examination of the patient and contrast-enhanced MRI of the spine. Patient data including tumor location and size, pathological diagnosis, intraoperative blood loss, operative time, postoperative time to mobilization, duration of hospitalization, and postoperative complications were collected. The extent of resection was assessed during surgery and was confirmed by using postoperative spinal MRI. At the last follow-up, clinical outcome was assessed using the visual analog scale (VAS) for pain and the American Spinal Injury Association (ASIA) scale for motor/sensory outcome.

\section{Operative Techniques}

After receiving general anesthesia, the patient was placed prone with all pressure points padded. A 4-cm skin incision was made in the midline centered over the lamina where the intradural tumor was located. To fully use the natural opening of the interlaminar space, which is widest at the center, the contralateral laminar space was usually exposed. The interspinous ligament was kept intact. Paraspinous musculature was stripped subperiosteally with monopolar cauterization, and, after placement of a retractor, the hemilamina above and below the target interlaminar space and the ligamentum flavum were exposed.

Then the microscope was mounted and the contralateral ligamentum flavum was resected piecemeal with a Kerrison rongeur. The dura and the arachnoid membrane underneath were then dissected in a standard longitudinal fashion, and a 4-0 suture was placed to pull away the dura to form a working window of approximately $1.5-2.0 \mathrm{~cm}$ in diameter (Fig. 1A and E). The intradural pathology was resected using a standard microsurgical technique. First, the lesion was identified among the spinal nerves by using a microsurgical probe, and with the help of a microaspirator, a surgical plane was then developed between the lesion and the spinal nerves. Caution was taken to identify the affected spinal nerve at the apex of the lesion, and sometimes it had to be removed because of its adherence to the lesion. Coagulation and cut-off of the feeding artery could lead to decreased blood perfusion of the lesion and facilitate the identification and separation of the efferent spinal nerve at the lower end of the lesion. Once the lesion was gently dissected from the spinal nerve on both ends, it was removed using an en bloc technique (Fig. 1B). When necessary, the lesion was resected in a piecemeal fashion using an ultrasonic aspirator.

If the interlaminar space was relatively small and/or the upper and lower ends of the lesion were located too far away from the interlaminar space to be observed and manipulated directly under the microscope, the authors chose to use endoscopic instruments for better access to the lesions and to minimize potential damage to the spinal cord. Specifically, when a dura opening of approximately $1.0 \mathrm{~cm}$ in diameter was achieved under the microscope, 


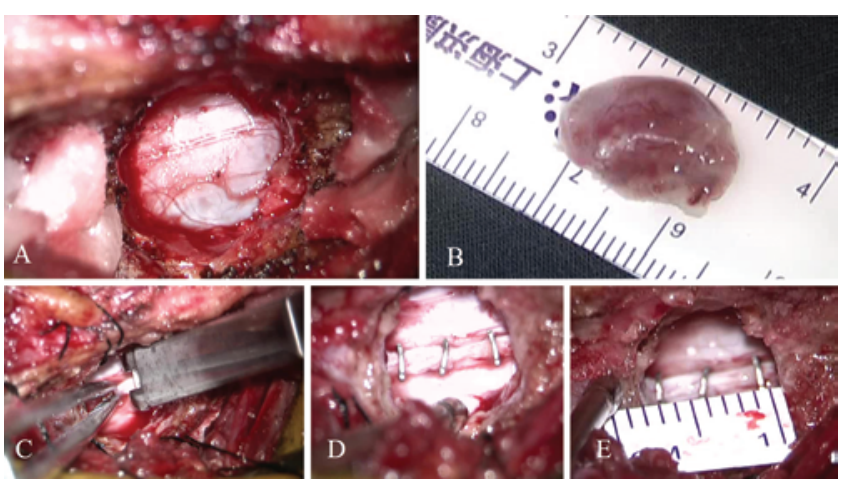

FIG. 1. Photographs of the operative procedures. A: The contralateral ligamentum flavum of the interlaminar space concerned was resected piecemeal with a Kerrison rongeur under the microscope. Usually the opening in the soft tissue was approximately $1.5-2.0 \mathrm{~cm}$ in diameter, depending on the size of the tumor underneath. B: Once the tumor was gently dissected from the spinal nerve on both upper and lower ends, it could then be removed by using an en bloc technique. C-E: The closure of the dura was achieved with application of titanium dural clips, and no incidence of postoperative CSF leak was observed. In the presented case, the opening measured less than $1 \mathrm{~cm}$.

a rigid endoscope was introduced through this working window and gently inserted into the contralateral subdural space. Isothermal normal saline (pressure at $100-150 \mathrm{~mm}$ $\mathrm{H}_{2} \mathrm{O}$ ) was used to irrigate the operative field. A small piece of gelatin foam was then inserted to provide a surgical plane between the lesion and nerves. The feeding artery and affected spinal nerves were coagulated and dissected by using a bipolar flexible radiofrequency probe. If the tumors were too large to be pulled out directly through the endoscopic canal, the endoscope was removed, and the tumors were resected microscopically with an ultrasonic aspirator. Once the tumor was resected, the dura was closed with titanium dural clips (Fig. 1C-E), and the suture line was reinforced with fibrin glue or gelatin foam to prevent epidural bleeding. The retractor and microscope were removed, the fascia and muscle were reapproximated with a 2-0 resorbable suture, and the subdermal region was reapproximated with a 3-0 resorbable suture. The skin was closed with 4-0 resorbable sutures using the subcuticular closure technique.

\section{Results}

Between October 2013 and March 2015, a total of 18 patients diagnosed with lumbar intradural-extramedullary tumors underwent minimally invasive treatment at the Department of Neurosurgery, Second Affiliated Hospital of Zhejiang University School of Medicine via interlaminar techniques, including 3 cases with intraoperative endoscopic assistance (Table 1). There were 12 men and 6 women with a mean age of 50 years (range 35-64 years). Gross-total resection (GTR) was achieved in all 18 patients. The average duration of surgery was 128 minutes (range 60-315 minutes), and the mean blood loss was 47 $\mathrm{ml}$ (range 20-100 ml; Table 2). There was only 1 patient who had procedure-related complications (urinary incontinence), but he recovered within 3 weeks after surgery. No incidence of postoperative CSF leak was observed in our study. Pathological reports identified benign schwan- nomas in 14 patients, and 2 ependymomas, 1 epidermoid cyst, and 1 enterogenous cyst. All patients were mobilized within 24 hours after surgery, and the mean length of hospitalization was 13 days (range 7-20 days). The mean MRI and clinical follow-up were 3.5 months (range 1-12 months) and 4.9 months (range 1-16 months), respectively. At last follow-up, 14 of the 18 patients had a reduced level of pain as suggested by an average VAS score that improved from 4.3 to 0.3 . The ASIA grade improved or remained normal in all patients except for 1 (Table 2).

\section{Illustrative Cases \\ Case 1}

A 59-year-old man with no medical history of note complained of approximately 10 years of left lower-limb pain, which had aggravated him for 1 month. There was no history of gait disturbance or bowel or bladder dysfunction. On physical examination, no sensory or motor deficits were found. The patient underwent lumbar contrast-enhanced MRI, which revealed an intradural-extramedullary tumor with cystic change at the L1-2 level (Fig. 2A-D). The patient underwent microsurgical tumor removal via the interlaminar approach, and postoperative MRI scans verified GTR (Fig. 2E and F). VRT reconstruction verified the intactness of the spinal lamina (Fig. $2 \mathrm{G}$ and $\mathrm{H}$ ). Pathological examination revealed the lesion to be a schwannoma. At follow-up, the patient's pain was completely resolved.

\section{Case 2}

A 39-year-old woman with no medical history of note complained of approximately 4 months of stiffness in her right upper thigh. She had no history of gait disturbance or bowel or bladder dysfunction. On physical examination, no sensory or motor deficits were found. The patient underwent lumbar contrast-enhanced MRI, which revealed an intradural-extramedullary tumor at the L1-2 level (Fig. $3 \mathrm{~A}-\mathrm{C})$. The patient underwent microsurgical tumor removal via the interlaminar approach, and postoperative MR images verified GTR (Fig. 3D). VRT reconstruction verified the intactness of the spinal lamina (Fig. 3E and F). Pathological examination revealed the lesion to be a schwannoma. At follow-up, the feeling of stiffness was completely resolved.

\section{Case 10}

A 60-year-old man with no medical history of note complained of approximately 1 month of right lower-limb pain. There was no history of gait disturbance or bowel or bladder dysfunction. On physical examination, sensory or motor deficits were not found. The patient underwent lumbar contrast-enhanced MRI, which revealed an intraduralextramedullary tumor at the L1-2 level and a herniated disk at the L4-5 level (Fig. 4A-C). The patient underwent removal of the tumor and the nucleus pulposus via endoscopic assistance, and postoperative MR images verified GTR (Fig. 4D). VRT reconstruction verified the intactness of the spinal lamina (Fig. 4E and F). Because the L1-2 interlaminar space was relatively small in the present case, instead of direct microsurgical resection, an endoscope 
TABLE 1. Demographic data of the 18 patients who underwent minimally invasive resection of intradural-extramedullary lumbar tumors via an interlaminar approach

\begin{tabular}{rcccccc}
\hline Case No. & Age (yrs), Sex & Location & Size $(\mathrm{mm})$ & VAS Score & Neurological Deficit (ASIA Grade) & Duration of Symptoms (mos) \\
\hline 1 & $59, \mathrm{M}$ & $\mathrm{L} 1-2$ & $10 \times 9 \times 39$ & 6 & $\mathrm{E}$ & 120 \\
\hline 2 & $39, \mathrm{~F}$ & $\mathrm{~L} 1-2$ & $10 \times 11 \times 15$ & 0 & $\mathrm{E}$ & 4 \\
\hline 3 & $61, \mathrm{M}$ & $\mathrm{L} 1-2$ & $10 \times 10 \times 20$ & 6 & $\mathrm{E}$ & 6 \\
\hline 4 & $55, \mathrm{M}$ & $\mathrm{L} 1-2$ & $8 \times 8 \times 14$ & 4 & $\mathrm{E}$ & 2 \\
\hline 5 & $36, \mathrm{~F}$ & $\mathrm{~L}-4$ & $9 \times 9 \times 11$ & 7 & Myelopathy, D & 6 \\
\hline 6 & $64, \mathrm{M}$ & $\mathrm{T} 12-\mathrm{L} 1$ & $18 \times 15 \times 59$ & 7 & $\mathrm{E}$ & 60 \\
\hline 7 & $48, \mathrm{~F}$ & $\mathrm{~L} 1-2$ & $8 \times 8 \times 7$ & 4 & Myelopathy, D & 2 \\
\hline 8 & $55, \mathrm{~F}$ & $\mathrm{~L} 1-2$ & $14 \times 14 \times 25$ & 7 & $\mathrm{E}$ & 3 \\
\hline 9 & $42, \mathrm{M}$ & $\mathrm{L}-4$ & $14 \times 12 \times 20$ & 6 & $\mathrm{E}$ & 1 \\
\hline 10 & $60, \mathrm{M}$ & $\mathrm{L} 1-2$ & $10 \times 11 \times 11$ & 6 & $\mathrm{E}$ & 1 \\
\hline 11 & $49, \mathrm{M}$ & T12-L1 & $10 \times 11 \times 11$ & 4 & $\mathrm{E}$ & 2 \\
\hline 12 & $46, \mathrm{M}$ & $\mathrm{L}-3$ & $18 \times 12 \times 19$ & 4 & $\mathrm{E}$ & 4 \\
\hline 13 & $44, \mathrm{~F}$ & $\mathrm{~L} 3-4$ & $12 \times 12 \times 15$ & 4 & $\mathrm{E}$ & 3 \\
\hline 14 & $48, \mathrm{M}$ & $\mathrm{L} 3-4$ & $13 \times 9 \times 20$ & 0 & $\mathrm{E}$ & 7 \\
\hline 15 & $51, \mathrm{M}$ & $\mathrm{L} 3-4$ & $17 \times 13 \times 18$ & 6 & $\mathrm{E}$ & 1 \\
\hline 16 & $50, \mathrm{~F}$ & $\mathrm{~L}-2$ & $7 \times 7 \times 10$ & 0 & $\mathrm{E}$ & 1 \\
\hline 17 & $60, \mathrm{M}$ & $\mathrm{L} 2-3$ & $6 \times 5 \times 7$ & 0 & 6 & 24 \\
\hline 18 & $35, \mathrm{M}$ & $\mathrm{L} 3-4$ & $9 \times 12 \times 33$ & 6 & & \\
\hline
\end{tabular}

was introduced into the dural opening to remove the tumor (Fig. 4G). Pathological examination revealed the lesion to be a schwannoma. At follow-up, the patient's lower-limb pain was completely resolved.

\section{Discussion}

Schwannomas are the most common intradural-extramedullary lesions of the lumbar spine, at approximately $50 \%$, and they are mostly benign tumors of the nerve sheath that grow slowly and can be satisfactorily treated with GTR. ${ }^{1,3,7,17,18}$ A traditional approach to lumbar intradural schwannomas involves a midline incision, bilateral muscle dissection, and removal of the posterior spinal elements. . $, 3,6,14,33$ Consequently, this approach might increase risks of postoperative spinal instability. Efforts have been made to improve the surgical technique from extensive laminectomy and facetectomy, to laminoplasty, hemilaminectomy, or even semihemilaminectomy. ${ }^{5,17,22,35,36,42}$ Although different surgical techniques have their own indications and contradictions, we should keep in mind that our priority sequence will always be the protection of the spinal cord and its function first, followed by prevention of postoperative spinal instability and deformity, and then minimization of the injuries to ligaments, muscle, and skin, if possible

The natural opening of the interlaminar space, especially the center portion, is actually wider than most of us had previously perceived. In Case 1, the tumor was located laterally under the interlaminar space. The classical surgical approach for its exposure is usually ipsilateral hemilaminectomy followed by partial or complete facetectomy. However, the authors chose the contralateral interlaminar approach to access this tumor instead. The advantage of this contralateral opening is full utilization of the widest center part of the interlaminar space for better exposure and resection of the lesion under a microscope. Therefore, this alternative minimally invasive interlaminar technique is expected to provide the same, if not better, protection to the spinal nerves as conventional techniques provide while maximally reducing bone tissue destruction.

In this series of 18 cases, 14 patients were pathologically diagnosed with benign schwannomas and the remaining 4 patients were diagnosed with 2 ependymomas, 1 epidermoid cyst, and 1 enterogenous cyst. Furthermore, the authors compared the results of the present study to results from their previous work reporting on semihemilaminectomy for the resection of a series of 24 intraspinal tumors. ${ }^{47}$ These previous data show that although there was no significant difference in tumor size between the 2 studies, the interlaminar procedure group had reduced intraoperative blood loss, postoperative confinement to bed, and length of hospitalization. In addition, the clinical outcome of the present series was comparable to outcomes with classic minimally invasive techniques. ${ }^{48}$

Spinal schwannoma are frequently associated with hemorrhage, intrinsic vascular changes, cyst formation, and fatty degeneration..$^{10,20,21}$ In the rare cases of cystic spinal schwannomas, the solid component of the tumors can be quite small. ${ }^{31,45}$ In Case 2, the lesion was $3.0 \mathrm{~cm}$ along the long axis, which exceeded the width of the interlaminar space. Therefore, the initial surgical plan was to remove the tumor via 2 adjacent interlaminar spaces. However, after exposure of the tumor through 1 interlaminar space and successful discharge of its cystic component, the lesion shrunk dramatically, and it was then possible to resect the tumor via this single interlaminar space. $\mathrm{Nev}$ ertheless, caution should still be taken, because in these patients the affected spinal nerve could be located distal to 
TABLE 2. Outcome of patients who underwent minimally invasive resection of intradural-extramedullary lumbar tumors via an interlaminar approach*

\begin{tabular}{|c|c|c|c|c|c|c|c|c|c|}
\hline \multirow[b]{2}{*}{$\begin{array}{l}\text { Case } \\
\text { No. }\end{array}$} & \multirow[b]{2}{*}{ Pathological Diagnosis } & \multirow[b]{2}{*}{$\begin{array}{l}\text { Op Time } \\
\text { (mins) }\end{array}$} & \multirow[b]{2}{*}{$\begin{array}{l}\text { EBL } \\
(\mathrm{ml})\end{array}$} & \multirow[b]{2}{*}{$\begin{array}{l}\text { LOS } \\
\text { (days) }\end{array}$} & \multicolumn{2}{|c|}{ Follow-Up (mos) } & \multirow[b]{2}{*}{$\begin{array}{c}\text { VAS Score } \\
\text { (preop/follow-up) }\end{array}$} & \multirow[b]{2}{*}{$\begin{array}{l}\text { ASIA Grade } \\
\text { (preop/postop) }\end{array}$} & \multirow[b]{2}{*}{ Complications } \\
\hline & & & & & Clinical & MRI & & & \\
\hline 1 & Schwannoma & 90 & 50 & 16 & 3 & 3 & $6 / 0$ & $E / E$ & No \\
\hline 2 & Schwannoma & 110 & 30 & 7 & 5 & 3 & $0 / 0$ & $E / E$ & No \\
\hline 3 & Schwannoma & 90 & 50 & 17 & 5 & 3 & $6 / 0$ & $E / E$ & No \\
\hline 4 & Ependymoma (WHO Grade II) & 140 & 50 & 13 & 5 & 3 & $4 / 0$ & $E / E$ & No \\
\hline 5 & Epidermoid cyst & 100 & 20 & 16 & 4 & 3 & $7 / 1$ & $E / E$ & No \\
\hline 6 & Schwannoma & 230 & 50 & 20 & 4.5 & 3 & $7 / 1$ & $\mathrm{D} / \mathrm{D}$ & Urinary incontinence \\
\hline 7 & Schwannoma & 125 & 50 & 9 & 5 & 3 & $4 / 0$ & $E / E$ & No \\
\hline 8 & Schwannoma & 110 & 50 & 11 & 2 & 1 & $7 / 1$ & $\mathrm{D} / \mathrm{E}$ & No \\
\hline 9 & Schwannoma & 70 & 50 & 11 & 1.5 & 1 & $6 / 0$ & $E / E$ & No \\
\hline 10 & Schwannoma & 315 & 50 & 17 & 2.5 & 1 & $6 / 1$ & $E / E$ & No \\
\hline 11 & Schwannoma & 113 & 50 & 15 & 8 & 6 & $4 / 0$ & $E / E$ & No \\
\hline 12 & Schwannoma & 60 & 20 & 8 & 1 & 1 & $4 / 0$ & $E / E$ & No \\
\hline 13 & Schwannoma & 120 & 50 & 11 & 1 & 1 & $4 / 0$ & $E / E$ & No \\
\hline 14 & Schwannoma & 165 & 30 & 11 & 1 & 1 & $0 / 0$ & $E / E$ & No \\
\hline 15 & Schwannoma & 100 & 50 & 10 & 8 & 6 & $6 / 0$ & $E / E$ & No \\
\hline 16 & Ependymoma (WHO Grade II) & 100 & 50 & 15 & 9 & 6 & $0 / 0$ & $E / E$ & No \\
\hline 17 & Enterogenous cyst & 170 & 100 & 15 & 6 & 6 & $0 / 0$ & $E / E$ & No \\
\hline 18 & Schwannoma & 100 & 50 & 15 & 16 & 12 & $6 / 1$ & $\mathrm{E} / \mathrm{E}$ & No \\
\hline
\end{tabular}

$\mathrm{EBL}=$ estimated blood loss; LOS = length of stay.

* All patients underwent GTR.
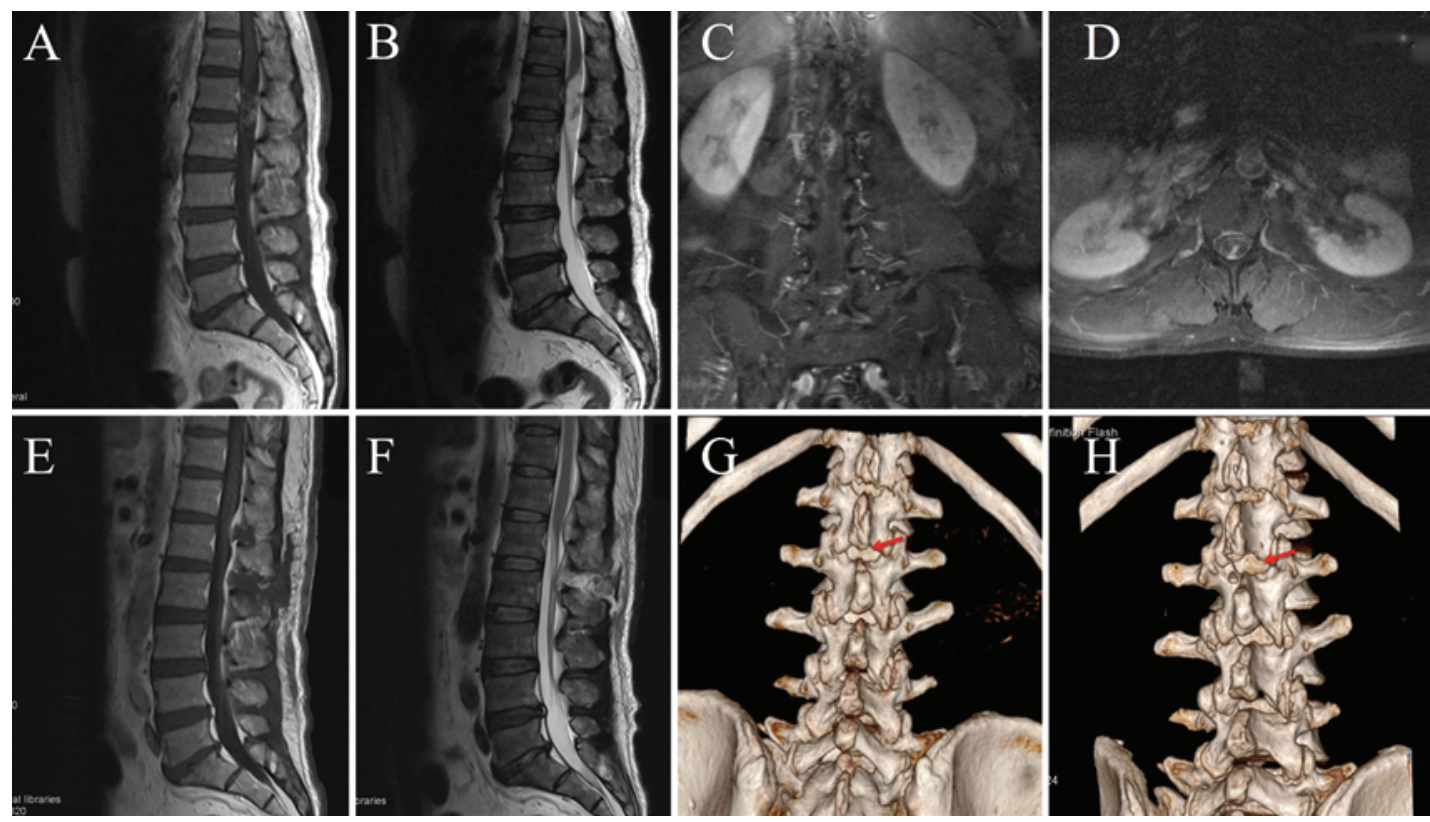

FIG. 2. Case 1. A-D: Preoperative T1-weighted contrast-enhanced (A: sagittal; C: coronal; D: axial) and T2-weighted (B) MR images suggest an L1-2 intradural-extramedullary schwannoma. E and F: Postoperative sagittal T1-weighted contrast-enhanced (E) and T2-weighted (F) MR images verified GTR of the tumor. G: Preoperative 3D CT reconstruction of the spinal canal with VRT suggests that the lesion was accessible via the contralateral L1-2 interlaminar space (arrow). H: Postoperative VRT reconstruction verified the intactness of the spinal lamina (arrow). 

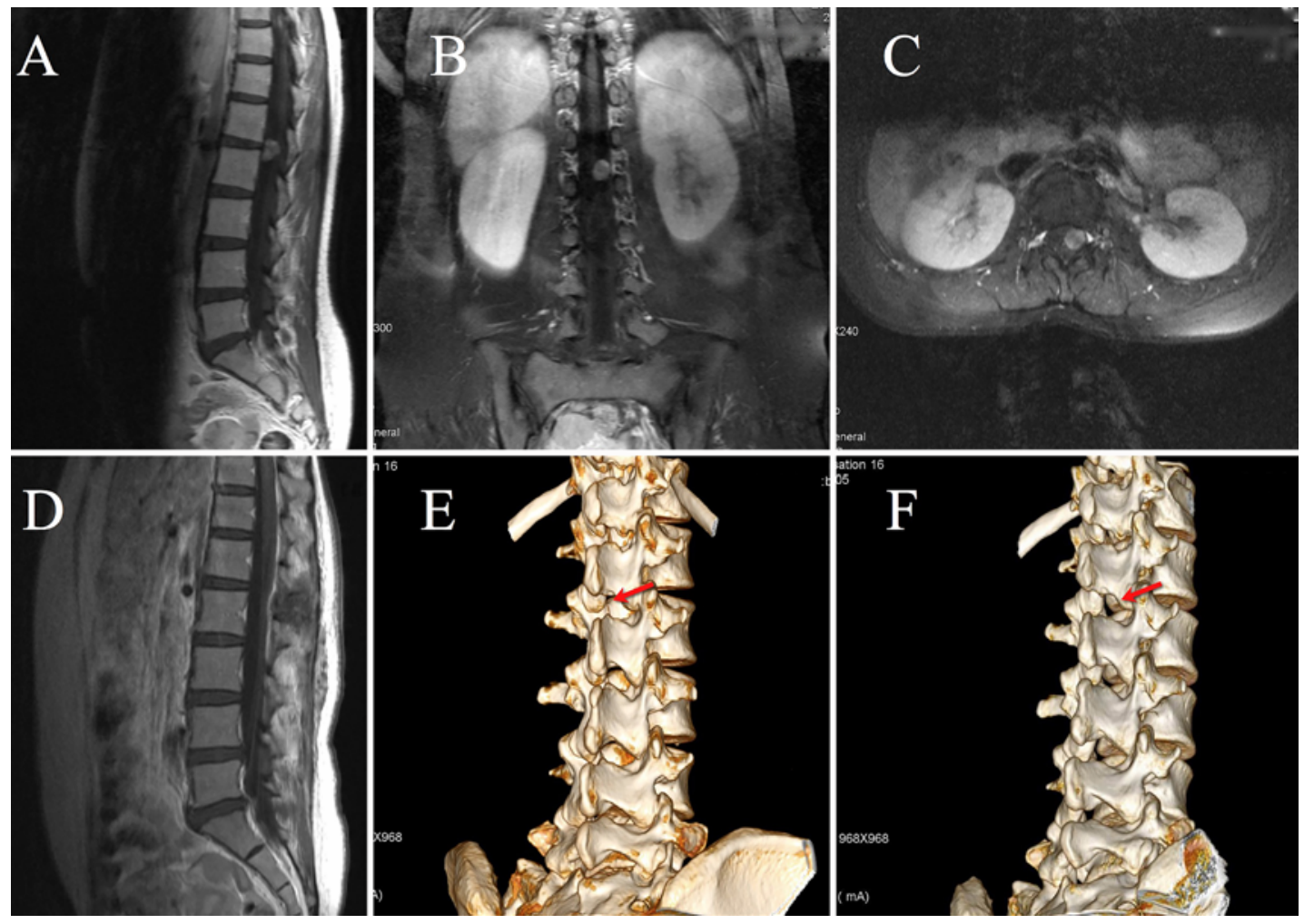

FIG. 3. Case 2. A-C: Preoperative T1-weighted contrast-enhanced MR images (A: sagittal; B: coronal; C: axial) suggest an L1-2 intradural-extramedullary schwannoma. D: A postoperative sagittal T1-weighted contrast-enhanced MR image verified GTR of the tumor. E: Preoperative 3D CT reconstruction of the spinal canal with VRT suggests that the lesion was accessible via the contralateral L1-2 interlaminar space (arrow). F: Postoperative VRT reconstruction verified the intactness of the spinal lamina (arrow).

the interlaminar space and even be adherent to the conus medullaris or the nerve root. For example, in Case 6, the postoperative complication of urinary incontinence might have been caused by intraoperative retraction of the conus medullaris that occurred when the interface between the tumor and its surrounding normal tissues gradually widened due to surgical maneuvers along the upper end of the tumor.

The relatively spacious lumbar spine makes it possible to endoscopically manage intradural lesions through the natural interlaminar space. The major obstacles that prevent the introduction of full endoscopic resection of intradural tumors into clinical practice might be related to factors such as excessive heavy bleeding from the epidural venous plexus, which could cause blurred images during the course of endoscopic surgery, and technical difficulties such as opening/retracting/closing of the dura using a full endoscope ${ }^{8,11,12,28,29,40,41}$ Accordingly, we modified the endoscopic surgery with microscope assistance; i.e., the endoscope was only introduced after the dura was opened and suspended under the microscope. For instance, in Cases 6,10, and 14, where the affected spinal nerves were located distal to the skin incision, it was quite difficult to discern anatomical features under the microscope. In addition, in Case 10, the preoperative VRT reconstruction indicated that the interlaminar space was too small for direct microscopic resection. However, with the help of the intraoperative endoscope, all 3 tumors located distal to the interlaminar space were successfully removed.
Except for those large schwannomas and ependymomas that occur in the conus medullaris, ${ }^{4,34,44}$ the authors endorse the surgical removal of lumbar intraspinal tumors through the interlaminar space. The core surgical techniques include the following: first, a strict selection criterion should be imposed in preoperative surgical planning. The indications for the interlaminar approach are those lumbar tumors that were revealed by preoperative radiological examinations to be small and oval to spindle shaped, or relatively large but with a significant cystic component. If the solid component of the lesion had a transverse diameter exceeding three-fourths of the diameter of the spinal canal, then it would be quite difficult to develop a surgical plane, significantly increasing the risks of spinal nerve injuries. Therefore, under such circumstances, we suggest the use of hemilaminectomy instead. Second, preoperative 3D CT reconstruction of the spinal canal with VRT might generate important anatomical information about the interlaminar space in question and allow emulation of the working conditions under a microscope. Third, CISS MRI sequences are helpful for determining the spatial relationship between the tumor and the affected spinal nerve root and are thus quite valuable for preoperative planning. Fourth, priority should be given to exposure and coagulation of the feeding artery at the upper (proximal) edge of the tumor during the operation. Because schwannomas generally rely on this downward blood supply for growth, this manipulation could effectively control tumor bleeding, render it possible for en bloc piecemeal tumor resec- 

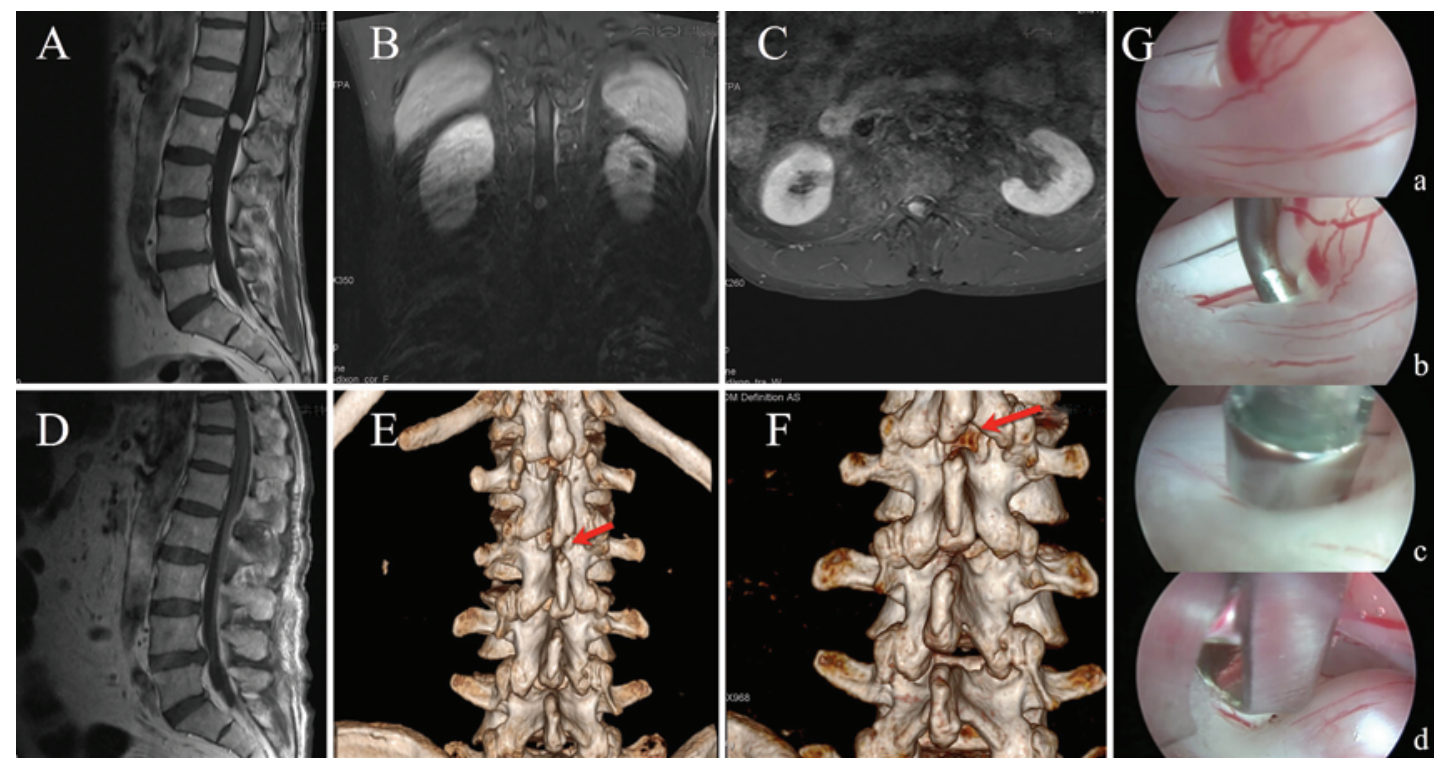

FIG. 4. Case 10. A-C: Preoperative T1-weighted contrast-enhanced MR images (A: sagittal; B: coronal; C: axial) suggest an L1-2 intradural-extramedullary schwannoma. D: A postoperative sagittal T1-weighted contrast-enhanced MR image verified GTR of the tumor. E: Preoperative 3D CT reconstruction of the spinal canal with VRT suggested that the lesion was accessible via the contralateral L1-2 interlaminar space (arrow). F: Postoperative VRT reconstruction verified the intactness of the spinal lamina (arrow). G: Because the L1-2 interlaminar space was relatively small in the present case, instead of direct microsurgical resection, an endoscope was introduced into the dura opening to expose (a), separate (b), coagulate (c), and then cut off (d) the tumor.

tion, or move the lesion to the next interlaminar space for excision. Finally, if difficulties appear during the operation, such as firm adhesion of the tumor to its surrounding spinal nerves, it would be reasonable to switch to a hemilaminectomy or laminectomy to minimize the risk of spinal nerve injury.

\section{Conclusions}

Most of the lumbar intraspinal tumors, especially schwannomas, could be safely and completely resected via a bone-sparing interlaminar approach. The indications for this novel approach (selection criteria) are lumbar tumors located near the interlaminar space and, according to preoperative radiological examinations, measuring less than $2 \mathrm{~cm}$ at the long axis diameter, or even more than $3 \mathrm{~cm}$ when a significant cystic component is present. With the aim to better protect neurological function, surgical planning should be individualized according to the anatomical features of the interlaminar space, and the tumor underneath should undergo thorough preoperative radiological characterization.

\section{References}

1. Aghayev K, Vrionis F, Chamberlain MC: Adult intradural primary spinal cord tumors. J Natl Compr Canc Netw 9:434-447, 2011

2. Ahn DK, Park HS, Choi DJ, Kim KS, Kim TW, Park SY: The surgical treatment for spinal intradural extramedullary tumors. Clin Orthop Surg 1:165-172, 2009

3. Altaş M, Cerçi A, Silav G, Sari R, Coşkun K, Balak N, et al: Microsurgical management of non-neurofibromatosis spinal schwannoma. Neurocirugia (Astur) 24:244-249, 2013

4. Ando K, Imagama S, Ito Z, Hirano K, Tauchi R, Muramoto
A, et al: Differentiation of spinal schwannomas and myxopapillary ependymomas: MR imaging and pathologic features. J Spinal Disord Tech 27:105-110, 2014

5. Angevine PD, Kellner C, Haque RM, McCormick PC: Surgical management of ventral intradural spinal lesions. J Neurosurg Spine 15:28-37, 2011

6. Arnautovic K, Arnautovic A: Extramedullary intradural spinal tumors: a review of modern diagnostic and treatment options and a report of a series. Bosn J Basic Med Sci 9 (Suppl 1):40-45, 2009

7. Chamberlain MC, Tredway TL: Adult primary intradural spinal cord tumors: a review. Curr Neurol Neurosci Rep 11:320-328, 2011

8. Chern JJ, Gordon AS, Naftel RP, Tubbs RS, Oakes WJ, Wellons JC III: Intradural spinal endoscopy in children. J Neurosurg Pediatr 8:107-111, 2011

9. Crispino M, Vecchioni S, Galli G, Olivetti L: Spinal intradural extramedullary haemangioma: MRI and neurosurgical findings. Acta Neurochir (Wien) 147:1195-1198, 2005

10. De Verdelhan O, Haegelen C, Carsin-Nicol B, Riffaud L, Amlashi SF, Brassier G, et al: MR imaging features of spinal schwannomas and meningiomas. J Neuroradiol 32:42-49, 2005

11. Di X: Endoscopic spinal tethered cord release: operative technique. Childs Nerv Syst 25:577-581, 2009

12. Endo T, Takahashi T, Jokura H, Tominaga T: Surgical treatment of spinal intradural arachnoid cysts using endoscopy. J Neurosurg Spine 12:641-646, 2010

13. Furtado SV, Murthy GK, Hegde AS: Cervical spine instability following resection of benign intradural extramedullary tumours in children. Pediatr Neurosurg 47:38-44, 2011

14. Ghadirpour R, Nasi D, Iaccarino C, Giraldi D, Sabadini R, Motti L, et al: Intraoperative neurophysiological monitoring for intradural extramedullary tumors: why not? Clin Neurol Neurosurg 130:140-149, 2015

15. Gu R, Liu JB, Xia P, Li C, Liu GY, Wang JC: Evaluation of hemilaminectomy use in microsurgical resection of intradural extramedullary tumors. Oncol Lett 7:1669-1672, 2014 
16. Gu R, Liu JB, Zhang Q, Liu GY, Zhu QS: MRI diagnosis of intradural extramedullary tumors. J Cancer Res Ther 10:927-931, 2014

17. Haji FA, Cenic A, Crevier L, Murty N, Reddy K: Minimally invasive approach for the resection of spinal neoplasm. Spine (Phila Pa 1976) 36:E1018-E1026, 2011

18. Hirano K, Imagama S, Sato K, Kato F, Yukawa Y, Yoshihara $\mathrm{H}$, et al: Primary spinal cord tumors: review of 678 surgically treated patients in Japan. A multicenter study. Eur Spine J 21:2019-2026, 2012

19. Huang WC, Wu JC, Chang PY, Tu TH, Yen YS, Cheng H: Complication avoidance in intradural extramedullary spinal tumors. J Neurosurg Spine 20:768-769, 2014

20. Jeon JH, Hwang HS, Jeong JH, Park SH, Moon JG, Kim CH: Spinal schwannoma; analysis of 40 cases. J Korean Neurosurg Soc 43:135-138, 2008

21. Kasliwal MK, Kale SS, Sharma BS, Suri V: Totally cystic intradural extramedullary schwannoma. Turk Neurosurg 18:404-406, 2008

22. Kim CH, Chung CK: Surgical outcome of a posterior approach for large ventral intradural extramedullary spinal cord tumors. Spine (Phila Pa 1976) 36:E531-E537, 2011

23. Kim SB, Kim HS, Jang JS, Lee SH: Mobility of intradural extramedullary schwannoma at spine: report of three cases with literature review. J Korean Neurosurg Soc 47:64-67, 2010

24. Li WS, Chen C, Wang H, Liang CF, Luo L, Guo Y: Hemilaminectomy approach combined with in situ restoration of vertebral laminae for thoracic intraspinal tumors. Turk Neurosurg 23:630-638, 2013

25. Liu GJ, Zhang SX, Qiu MG, Tan LW, Li QY, Li K: A novel technique for three-dimensional reconstruction for surgical simulation around the craniocervical junction region. Int Surg 96:274-280, 2011

26. Mannion RJ, Nowitzke AM, Efendy J, Wood MJ: Safety and efficacy of intradural extramedullary spinal tumor removal using a minimally invasive approach. Neurosurgery 68 (1 Suppl Operative):208-216, 2011

27. Marchetti M, De Martin E, Milanesi I, Fariselli L: Intradural extramedullary benign spinal lesions radiosurgery. Mediumto long-term results from a single institution experience. Acta Neurochir (Wien) 155:1215-1222, 2013

28. Mauer UM, Gottschalk A, Kunz U, Schulz C: Arachnoscopy: a special application of spinal intradural endoscopy. Neurosurg Focus 30(4):E7, 2011

29. Maxmauer U, Danz B, Gottschalk A, Kunz U: Endoscopeassisted surgery of spinal intradural adhesions in the presence of cerebrospinal fluid flow obstruction. Spine (Phila Pa 1976) 36:E773-E779, 2011

30. Mehta AI, Adogwa O, Karikari IO, Thompson P, Verla T, Null UT, et al: Anatomical location dictating major surgical complications for intradural extramedullary spinal tumors: a 10-year single-institutional experience. J Neurosurg Spine 19:701-707, 2013

31. Netra R, Hui MS, Gang MZ, Ming Z: Spinal cystic schwannoma: an MRI evaluation. J Coll Physicians Surg Pak 24:145-147, 2014

32. Ozawa H, Onoda Y, Aizawa T, Nakamura T, Koakutsu T, Itoi E: Natural history of intradural-extramedullary spinal cord tumors. Acta Neurol Belg 112:265-270, 2012

33. Sachdev S, Dodd RL, Chang SD, Soltys SG, Adler JR, Luxton G, et al: Stereotactic radiosurgery yields long-term control for benign intradural, extramedullary spinal tumors. Neurosurgery 69:533-539, 2011

34. Sasani M, Sasani H, Kaner T, Fahir Ozer A: Resection of a large spinal intradural ependymoma using a limited unilateral laminectomy approach in the lumbosacral region. J Neurosurg Sci 56:55-59, 2012

35. Sharifi G, Mortaz M, Parsaei B: Multiple intradural extra- medullary tumours presenting with paraplegia after trauma. Acta Neurochir (Wien) 151:697-698, 2009

36. Sim JE, Noh SJ, Song YJ, Kim HD: Removal of intraduralextramedullary spinal cord tumors with unilateral limited laminectomy. J Korean Neurosurg Soc 43:232-236, 2008

37. Smith ZA, Aoun SG, Y El Ahmadieh T, Wong AP, Lall RR, Bendok BR, et al: Minimally invasive resection of a highthoracic intradural extramedullary tumor: an operative 3-D video. Neurosurgery 73 (1 Suppl Operative):ons1, 2013 (Erratum in Neurosurgery 73:E913, 2013)

38. Tan LA, Kasliwal MK, Wewel J, Fontes RB, O’Toole JE: Minimally invasive surgery for synchronous, same-level lumbar intradural-extramedullary neoplasm and acute disc herniation. Neurosurg Focus 37 Suppl 2:Video 16, 2014

39. Tarantino R, Donnarumma P, Nigro L, Rullo M, Santoro A, Delfini R: Surgery of intradural extramedullary tumors: retrospective analysis of 107 cases. Neurosurgery 75:509-514, 2014

40. Thongrong C, Kasemsiri P, Carrau RL, Bergese SD: Control of bleeding in endoscopic skull base surgery: current concepts to improve hemostasis. ISRN Surg 2013:191543, 2013

41. Tredway TL, Musleh W, Christie SD, Khavkin Y, Fessler RG, Curry DJ: A novel minimally invasive technique for spinal cord untethering. Neurosurgery 60 (2 Suppl 1):ONS70ONS74, 2007

42. Tredway TL, Santiago P, Hrubes MR, Song JK, Christie SD, Fessler RG: Minimally invasive resection of intraduralextramedullary spinal neoplasms. Neurosurgery 58 (1 Suppl):ONS52-ONS58, 2006

43. Weber C, Gulati S, Jakola AS, Habiba S, Nygaard OP, Johannesen $\mathrm{TB}$, et al: Incidence rates and surgery of primary intraspinal tumors in the era of modern neuroimaging: a national population-based study. Spine (Phila Pa 1976) 39:E967E973, 2014

44. Wostrack M, Shiban E, Obermueller T, Gempt J, Meyer B, Ringel F: Conus medullaris and cauda equina tumors: clinical presentation, prognosis, and outcome after surgical treatment: clinical article. J Neurosurg Spine 20:335-343, 2014

45. Wu D, Ba Z, Huang Y, Zhao W, Shen B, Kan H: Totally cystic schwannoma of the lumbar spine. Orthopedics 36:e679e682, 2013

46. Yu Y, Zhang X, Hu F, Xie T, Gu Y: Minimally invasive microsurgical treatment of cervical intraspinal extramedullary tumors. J Clin Neurosci 18:1168-1173, 2011

47. Zhu YJ, Tang ZX, Wang LL, Zhu LL, Shen H, Zhang JM: Microsurgical resection of spinal intradural extramedullary tumors by hemi-semi-laminectomy. Chinese J Neurosurg 30:694-697, 2014

48. Zong S, Zeng G, Du L, Fang Y, Gao T, Zhao J: Treatment results in the different surgery of intradural extramedullary tumor of 122 cases. PLoS One 9:e111495, 2014

49. Zong S, Zeng G, Xiong C, Wei B: Treatment results in the differential surgery of intradural extramedullary schwannoma of 110 cases. PLoS One 8:e63867, 2013

\section{Author Contributions}

Conception and design: YJ Zhu, Shen. Acquisition of data: YJ Zhu, Ying, Chen, LL Wang, Ren, C Wang. Analysis and interpretation of data: YJ Zhu, Ying, Chen, LL Wang, Shen. Drafting the article: YJ Zhu, Shen. Critically revising the article: Zhang. Administrative/technical/material support: LL Zhu, Wu. Study supervision: LL Zhu, Zhang.

\section{Correspondence}

Yong-Jian Zhu, Department of Neurosurgery, Second Affiliated Hospital of Zhejiang University School of Medicine, 88 Jiefang Rd., Hangzhou, Zhejiang 310000, China. email: neurosurgery@ zju.edu.cn. 